\title{
MILHO PIPOCA: CARACTERIZAÇÃO FÍSICA, QUÍMICA, MICROBIOLÓGICA E SENSORIAL
}

\author{
UBIRACIRA FERREIRA TISSOT * \\ RUI CARLOS ZAMBIAZI ** \\ CARLA ROSANE BARBOZA MENDONÇA ***
}

\begin{abstract}
Visou-se caracterizar física, química, microbiológica e sensorialmente o milho pipoca, produzido na serra gaúcha e compará-lo com amostras comerciais importadas. Também caracterizou-se física e sensorialmente o milho pipoca após o processo de expansão. Os resultados evidenciaram grande similaridade entre as características de todas amostras, tanto para os grãos in natura quanto para os grãos expandidos. A maior diferença observada sensorialmente envolveu o atributo cor. Concluiu-se que o milho pipoca produzido na região serrana do Estado do Rio Grande do Sul apresenta qualidade similar ao milho pipoca importado.
\end{abstract}

\section{INTRODUÇÃO}

Os grãos de cereais constituem valiosa fonte de proteínas para a alimentação humana, embora seu principal constituinte, em termos quantitativos, seja o amido (HOSENEY, 1991). Os cereais mais importantes no Brasil, econômica e nutricionalmente são o trigo, o arroz e o milho. Como os demais tipo de milho, o milho pipoca pertence a espécie botânica Zea Mays L. Caracteriza-se por apresentar sementes duras e pequenas, que sob ação do calor se expandem, originando a pipoca. Sua característica de expansão o diferencia dos demais tipos de milhos, fazendo com que seja largamente apreciado e consumido como guloseima (FACHIN et al., 1993).

* Economista Doméstica, Departamento de Ciência dos Alimentos, Faculdade de Ciências Domésticas, Universidade Federal de Pelotas, Pelotas/RS.

** Químico Industrial, Dr. em Food and Nutritional Science, Departamento de Ciência dos Alimentos, Universidade Federal de Pelotas. (e-mail: zambiazi@ufpel.tche.br).

*** Economista Doméstica, Mestre em Ciências, Doutoranda em Química, Departamento de Química Orgânica, Universidade Federal de Pelotas.

(e-mail: sidcar@ufpel.tche.br). 
A capacidade do milho pipoca em se expandir, sob aquecimento, é explicada pela resistência do pericarpo, associada à presença de óleo e de umidade no grão. Quando aquecido em temperatura apropriada, o óleo e a umidade exercem forte pressão sobre o pericarpo, cujo rompimento expõe o endosperma (FACHIN et al., 1993).

Utilizado desde muito pelos indígenas como fonte de alimento, e muito ligado a tradição popular, este tipo de milho vem despertando crescente atenção. Até bem pouco tempo, as sementes do milho pipoca disponíveis no comércio brasileiro eram importadas em razão da inexistência de cultivares adequados às necessidades dos produtores. Em função disso, algumas instituições e empresas produtoras de sementes passaram a dedicar-Ihe mais atenção, assim como os produtores que visualizaram fonte de renda compensadora (GUADAGNIN, 1996).

A completa caracterização física, química, microbiológica e sensorial do milho pipoca ainda é desconhecida em relação a muitas variedades que estão sendo utilizadas no comércio brasileiro. Desta forma, este trabalho teve como objetivo determinar as características físicas, químicas e microbiológicas de grãos de milho pipoca produzidos na região serrana do Rio Grande do Sul, além de avaliar física e sensorialmente o milho pipoca após o processo de expansão.

\section{MATERIAL E MÉTODOS}

\subsection{MATÉRIA-PRIMA}

Foram coletados $10 \mathrm{~kg}$ de grãos de milho pipoca tipo híbrido, de duas cultivares e de 10 produtores da cidade de Nova Prata, localizada na região serrana do Rio Grande do Sul. As amostras foram identificadas pelos códigos de $A_{1}$ a $A_{10}$. As sementes utilizadas no plantio foram importadas da Argentina e fornecidas pela empresa Alumini Seed (Nova Prata/RS). A colheita foi realizada entre os meses de abril e maio de 1999. Além destas, foram adquiridas para fins de comparação, outras duas amostras no comércio local, sendo as mesmas de milho pipoca importado, que foram codificadas como $A_{11}$ e $A_{12}$.

\subsection{ANÁLISES DO MILHO PIPOCA}

\subsubsection{Análises físicas}

As análises físicas, envolvendo forma, tamanho, cor e peso, seguiram as recomendações descritas por CAMPBELL; PENFIELD \& GRISWOLD (1979). A forma foi determinada, visualmente, separando-se os grãos em 
grupos, segundo três classificações, ou seja, arredondada, chata e pontuda. O tamanho também foi verificado visualmente. Para cada uma das amostras, 100 grãos de milho pipoca foram classificados pelo tamanho em três grupos, considerando as medidas de largura e comprimento. Após contagem do número de grãos, em cada um dos três grupos efetuou-se a média ponderada para cada amostra. Para determinação da cor, os grãos foram agrupados em quatro classificações visuais, codificadas de 1 a 4 , sendo a classificação 1 amarelo claro e 4 amarelo intenso. Para cada amostra, 100 grãos foram separados segundo a intensidade de cor, dentro dos quatro grupos. O peso foi determinado em balança semi-analítica, a partir da pesagem de $100 \mathrm{~mL}$ de grãos, medidos em proveta. Efetuou-se ainda, a contagem e separação dos grãos estragados e/ou quebrados presentes em $100 \mathrm{~mL}$ de cada amostra.

\subsubsection{Análises físico-químicas}

As análises físico-químicas seguiram os procedimentos descritos pelas normas analíticas do INSTITUTO ADOLFO LUTZ (1985), tendo sido realizadas as determinações de proteína, lipídios, fibra, acidez, cinzas e umidade.

\subsubsection{Análises microbiológicas}

Foram realizadas as determinações de coliformes totais e coliformes fecais pelo método do número mais provável (NMP), segundo metodologia do Bacteriological Analytical Manual for Foods (FDA, 1992).

\subsection{PROCESSO DE EXPANSÃO}

O processo de expansão foi realizado de forma padronizada para todas as amostras, em panela pipoqueira (própria para o preparo de pipocas, com rotação manual). A quantidade de óleo utilizada foi de $10 \mathrm{~g}$ para cada $90 \mathrm{~g}$ de milho pipoca. Aqueceu-se o óleo por 1 minuto em fogo alto, adicionouse o milho pipoca, diminuiu-se a intensidade do fogo e agitou-se o milho no sentido horário até o final da expansão. $O$ tempo total para expansão girou em torno de 2 minutos para todas as amostras.

\subsection{ANÁLISE DO MILHO PIPOCA EXPANDIDO}

\subsubsection{Análises físicas}

As análises físicas, envolvendo peso após a expansão, número de grãos não expandidos e tamanho final, seguiram as recomendações descritas 
por CAMPBELL; PENFIELD \& GRISWOLD (1979). Determinou-se o peso após expansão em balança semi analítica (precisão $\pm 0,01 \mathrm{~g}$ ). O número de grãos não expandidos foi contabilizado, individualmente, após o processo de expansão. O tamanho final foi obtido pela medida da largura e comprimento de 10 pipocas expandidas de cada amostra, efetuando-se média aritmética.

\subsubsection{Análise sensorial}

A análise sensorial envolveu o teste de avaliação de atributos, utilizando-se equipe de 12 julgadores treinados, sendo 11 do sexo feminino e 1 do sexo masculino, com idades entre 15 e 50 anos. Foram avaliados os atributos cor, expansão e maciez, mediante escalas não estruturadas de $9 \mathrm{~cm}$, segundo metodologia da Associação Brasileira de Normas Técnicas (ABNT, 1993; 1998) e SZCZESNIAK (1963). Para o atributo expansão, os extremos da escala foram definidos como: sem expansão (zero) e expandido (9), para o atributo cor os extremos foram branca (zero) e amarela (9), e para maciez, macio (zero) e duro (9).

As amostras foram apresentadas aos julgadores em recipientes de porcelana branca, codificados com número de 3 dígitos aleatórios, segundo recomendações da International Organization for Standardization (ISO, 1982).

\subsection{ANÁLISE ESTATÍSTICA}

O estudo estatístico foi realizado empregando-se a análise de variância e a comparação de médias efetuada pelo teste de Tukey, ao nível de 5\% de probabilidade (STATSOFT, 1991).

\section{RESULTADOS E DISCUSSÕES}

\subsection{CARACTERÍSTICAS DO MILHO PIPOCA}

\subsubsection{Avaliação física}

A Tabela 1 apresenta os resultados das avaliações físicas realizadas com o milho pipoca.

Todas as amostras apresentaram forma similar (arredondada), exceto a amostra $A_{6}$ (pontuda).

Das 10 amostras pertencentes às duas cultivares coletadas na região serrana do Rio Grande do Sul, 9 amostras ficaram entre 75\% e 85\% na classificação 2 da cor, o que demonstra homogeneidade para esta 
característica. A amostra $A_{6}$ apresentou coloração amarela mais intensa, ficando com $50 \%$ na faixa 3 da cor.

TABELA 1 - CARACTERÍSTICAS FÍSICAS DO MILHO PIPOCA

\begin{tabular}{|c|c|c|c|c|c|c|c|c|c|}
\hline \multirow{3}{*}{ Amostra } & \multicolumn{9}{|c|}{ Avaliações } \\
\hline & \multirow{2}{*}{ Forma } & \multicolumn{3}{|c|}{ Cor * } & \multirow{2}{*}{\multicolumn{2}{|c|}{$\begin{array}{l}\text { Tamanho } \\
(\mathrm{cm})\end{array}$}} & \multirow{2}{*}{$\begin{array}{c}\mathrm{n}^{\circ} \\
\text { grãos c/ } \\
\text { defeito }\end{array}$} & \multirow{2}{*}{$\begin{array}{l}\mathrm{n}^{\mathrm{o}} \text { grãos } \\
\text { quebrados }\end{array}$} & \multirow{2}{*}{$\begin{array}{r}\text { Peso }(\mathrm{g} \\
100 \mathrm{~mL} \\
\text { grãos }\end{array}$} \\
\hline & & 1 & 2 & 34 & & & & & \\
\hline $\mathrm{A}_{1}$ & arredondado & 14 & 85 & - & - & 0,63 & 1 & 0 & 13,62 \\
\hline $\mathrm{A}_{2}$ & arredondado & 14 & 82 & - & - & 0,61 & 4 & 0 & 15,29 \\
\hline $\mathrm{A}_{3}$ & arredondada & 12 & 83 & - & - & 0,63 & 4 & 1 & 15,97 \\
\hline $\mathrm{A}_{4}$ & arredondado & 17 & 78 & - & - & 0,61 & 3 & 2 & 14,05 \\
\hline $\mathrm{A}_{5}$ & arredondado & 14 & 84 & - & - & 0,61 & 2 & 0 & 13,94 \\
\hline $\mathrm{A}_{6}$ & pontudo & 13 & 28 & 50 & 7 & 0,68 & 2 & 0 & 15,62 \\
\hline $\mathrm{A}_{7}$ & arredondado & 18 & 75 & - & - & 0,63 & 4 & 3 & 12,30 \\
\hline $\mathrm{A}_{8}$ & arredondado & 17 & 75 & - & - & 0,63 & 7 & 1 & 15,79 \\
\hline $\mathrm{A}_{9}$ & arredondado & 13 & 84 & - & - & 0,62 & 3 & 0 & 15,08 \\
\hline $\mathrm{A}_{10}$ & arredondado & 10 & 82 & - & - & 0,58 & 4 & 4 & 12,42 \\
\hline $\mathrm{A}_{11}$ & arredondado & 12 & 83 & - & - & 0,71 & 5 & 0 & 16,64 \\
\hline $\mathrm{A}_{12}$ & arredondado & 14 & 83 & - & - & 0,61 & 3 & 0 & 12,49 \\
\hline
\end{tabular}

* Especificação dos valores 1,2,3,4 em material e métodos.

Quanto ao tamanho houve grande similaridade entre as amostras (faixa 0,58 a $0,68 \mathrm{~cm}$ ), exceto para a amostra $A_{11}$, cujo tamanho atingiu média de $0,71 \mathrm{~cm}$.

Observou-se que o número de grãos defeituosos foi inferior a $5 \%$, com exceção da amostra $A_{8}(7 \%)$. O termo defeituoso refere-se a grãos que apresentaram qualquer defeito físico, mas que não foram descartados para o processo de expansão. Da mesma forma, para o número de grãos quebrados, nenhuma amostra apresentou valor superior a $4 \%$ e também foram utilizados normalmente para a expansão. A soma dos grãos defeituosos e quebrados não ultrapassou $8 \%$ entre todas as amostras, demonstrando boa qualidade física dos grãos de milho pipoca.

O peso apresentado por todas as amostras (100 grãos) não foi superior a $16,64 \mathrm{~g}$ nem inferior a $12,30 \mathrm{~g}$. A amostra $A_{11}$, que se caracterizou pelo maior tamanho, também apresentou o maior peso percentual. No entanto, 
a mesma correlação não foi observada para a amostra $A_{10}$, que apresentou o menor tamanho, mas não o menor peso.

\subsubsection{Avaliações químicas}

Os resultados das análises físico-químicas do milho pipoca encontram-se na Tabela 2.

\section{TABELA 2 - CARACTERÍSTICAS FÍSICO-QUÍMICAS DO MILHO PIPOCA}

\begin{tabular}{ccccccc}
\hline & \multicolumn{5}{c}{ Determinações } \\
\cline { 2 - 7 } Amostras & Fibra (\%) & $\begin{array}{c}\text { Cinza } \\
(\%)\end{array}$ & Umidade $(\%)$ & $\begin{array}{c}\text { Acidez } \\
(\% \mathrm{NaOH})\end{array}$ & $\begin{array}{c}\text { Lipídios } \\
(\%)\end{array}$ & Proteína (\%) \\
\hline $\mathrm{A}_{1}$ & $1.19 \mathrm{ac}$ & $1.31 \mathrm{a}$ & $13.65 \mathrm{acd}$ & $0,38 \mathrm{ac}$ & $2.50 \mathrm{a}$ & $10.12 \mathrm{abdfh}$ \\
$\mathrm{A}_{2}$ & $2.93 \mathrm{bc}$ & $1.31 \mathrm{a}$ & $12.00 \mathrm{~b}$ & $0,48 \mathrm{adg}$ & $3.07 \mathrm{a}$ & $9.36 \mathrm{abfh}$ \\
$\mathrm{A}_{3}$ & $2.22 \mathrm{ce}$ & $1.11 \mathrm{a}$ & $13.82 \mathrm{acd}$ & $0,48 \mathrm{adg}$ & $3.09 \mathrm{a}$ & $10.51 \mathrm{acdf}$ \\
$\mathrm{A}_{4}$ & $2.18 \mathrm{ec}$ & $1.13 \mathrm{a}$ & $13.89 \mathrm{acd}$ & $0,95 \mathrm{~b}$ & $3.02 \mathrm{a}$ & $10.17 \mathrm{abdfh}$ \\
$\mathrm{A}_{5}$ & $2.38 \mathrm{ec}$ & $1.07 \mathrm{a}$ & $14.33 \mathrm{ad}$ & $0,38 \mathrm{a}$ & $2.93 \mathrm{a}$ & $9.08 \mathrm{bgi}$ \\
$\mathrm{A}_{6}$ & $2.27 \mathrm{ec}$ & $1.29 \mathrm{a}$ & $13.51 \mathrm{cde}$ & $0,52 \mathrm{cdf}$ & $4.49 \mathrm{bc}$ & $11.47 \mathrm{ce}$ \\
$\mathrm{A}_{7}$ & $2.12 \mathrm{ec}$ & $1.30 \mathrm{a}$ & $12.05 \mathrm{~b}$ & $0,48 \mathrm{ach}$ & $3.27 \mathrm{a}$ & $11.15 \mathrm{def}$ \\
$\mathrm{A}_{8}$ & $2.03 \mathrm{de}$ & $1.12 \mathrm{a}$ & $14.06 \mathrm{~d}$ & $0,67 \mathrm{eik}$ & $3.63 \mathrm{a}$ & $10.36 \mathrm{defj}$ \\
$\mathrm{A}_{9}$ & $2.32 \mathrm{ec}$ & $1.04 \mathrm{a}$ & $13.72 \mathrm{~d}$ & $0,62 \mathrm{fj}$ & $3.39 \mathrm{a}$ & $9.53 \mathrm{fgj}$ \\
$\mathrm{A}_{10}$ & $1.92 \mathrm{de}$ & $1.17 \mathrm{a}$ & $12.87 \mathrm{e}$ & $0,57 \mathrm{ghij}$ & $3.07 \mathrm{ab}$ & $9.68 \mathrm{fgj}$ \\
$\mathrm{A}_{11}$ & $1.84 \mathrm{de}$ & $1.30 \mathrm{a}$ & $12.83 \mathrm{e}$ & $0,76 \mathrm{k}$ & $3.17 \mathrm{ac}$ & $9.90 \mathrm{fgj}$ \\
$\mathrm{A}_{12}$ & $1.98 \mathrm{e}$ & $1.11 \mathrm{a}$ & $13.61 \mathrm{~d}$ & $0,76 \mathrm{k}$ & $3,85 \mathrm{a}$ & $9.31 \mathrm{hij}$ \\
\hline
\end{tabular}

Letras diferentes na mesma coluna indicam diferença estatisticamente significativa, pelo teste de Tukey, ao nível de $5 \%$ de probabilidade.

O teor de fibra variou de 1,19 a 2,93\%, com pouca diferença significativa, evidenciando similaridade entre as amostras.

Quanto ao teor de cinzas não houve diferença significativa entre as amostras (valores entre 1,04 a 1,31\%).

O conteúdo de umidade ficou na faixa de 12,00 a $14,33 \%$ e portanto, superior ao recomendado para milho pipoca que é de $10 \%$. Teores de umidade superiores a $15 \%$ podem acelerar as contaminações por fungos (POMERANZ, 1991).

A variabilidade no índice de acidez, entre 0,38\% e 0,95\%, apresentou diferença significativa entre as amostras. Resultados similares foram obtidos para o percentual de lipídios, sendo que apenas as amostras $A_{6}$, $A_{10}$ e $A_{11}$ apresentaram diferença significativa. $O$ teor de lipídios 
apresentou-se relativamente superior ao de cereais em geral, cuja faixa média é de $2 \%$ (POMERANZ, 1991).

Verificou-se diferença significativa entre as amostras na determinação de proteína, embora os valores tenham se apresentado bem próximos. Devese salientar o alto conteúdo protéico do milho pipoca, superior aos cereais em geral, que normalmente não ultrapassa 6\% (POMERANZ, 1991).

\subsubsection{Avaliação microbiológica}

Os resultados apresentados na Tabela 3 referem-se as análises microbiológicas realizadas nos grãos de milho pipoca.

\section{TABELA 3 - CARACTERÍSTICAS MICROBIOLÓGICAS DO MILHO PIPOCA}

\begin{tabular}{|c|c|c|c|c|c|c|c|c|c|c|c|c|}
\hline \multirow[b]{2}{*}{ Análises } & \multicolumn{12}{|c|}{ Amostras } \\
\hline & $\mathrm{A}_{1}$ & $\mathrm{~A}_{2}$ & $A_{3}$ & $\mathrm{~A}_{4}$ & $\mathrm{~A}_{5}$ & $\mathrm{~A}_{6}$ & $\mathrm{~A}_{7}$ & $\mathrm{~A}_{8}$ & $\mathrm{~A}_{9}$ & $\mathrm{~A}_{10}$ & $\mathrm{~A}_{11}$ & $\mathrm{~A}_{12}$ \\
\hline $\begin{array}{c}\text { Coliformes } \\
\text { Totais } \\
\text { (NMP/g) }\end{array}$ & 23 & 23 & 23 & 23 & 23 & $<3$ & 23 & 23 & $<3$ & $<3$ & $<3$ & 23 \\
\hline $\begin{array}{l}\text { Coliformes } \\
\text { Fecais } \\
(\mathrm{NMP} / \mathrm{g})\end{array}$ & $<3$ & $<3$ & $<3$ & $<3$ & $<3$ & $<3$ & $<3$ & $<3$ & $<3$ & $<3$ & $<3$ & $<3$ \\
\hline
\end{tabular}

$\mathrm{NMP} / \mathrm{g}=$ Número mais provável por grama .

A contaminação por coliformes totais apresentou níveis muito baixos, os quais não oferecem riscos a saúde do consumidor, estando de acordo com os padrões da legislação vigente (BRASIL, 2001). Quanto a coliformes fecais, todas as amostras apresentaram resultados negativos, correspondendo a $<3 \mathrm{NMP} / \mathrm{g}$.

\subsection{AVALIAÇÃO DOS GRÃOS DE MILHO PIPOCA EXPANDIDO}

A Tabela 4 apresenta as características físicas do milho pipoca após a expansão.

Observou-se pequena alteração no peso do milho pipoca antes e após a expansão, possivelmente, devido a pequena absorção de gordura durante a expansão dos grãos. 
O número de grãos não expandidos enquadrou-se em faixas inferiores a 4 , com exceção da amostra $A_{2}$, que apresentou número de não expandidos igual a 7. Observou-se pequena diferença na taxa de expansão, destacando-se as amostras $A_{1}, A_{4}, A_{8}, A_{10}$ e $A_{12}$ que obtiveram maiores índices de expansão (relação tamanho final/tamanho inicial). As amostras $A_{3}$ e $A_{11}$ foram as que menos se expandiram. A média de incremento de tamanho após o processo de expansão ficou na faixa de $1,2 \mathrm{~cm}$, ou seja aumento de tamanho da ordem de $93 \%$.

\section{TABELA 4 - CARACTERÍSTICAS FÍSICAS DO MILHO PIPOCA APÓS A EXPANSÃO}

\begin{tabular}{cccccc}
\hline & \multicolumn{5}{c}{ Determinações } \\
\cline { 2 - 6 } Amostra & $\begin{array}{c}\text { Peso } 1 *^{1} \\
(\mathrm{~g})\end{array}$ & $\begin{array}{c}\text { Peso } 2 *^{2} \\
(\mathrm{~g})\end{array}$ & $\begin{array}{c}\mathrm{n}^{\text {o }} \text { de não } \\
\text { expandidos*3 }\end{array}$ & $\begin{array}{c}\text { Tamanho } \\
\text { final }(\mathrm{cm})\end{array}$ & $\begin{array}{c}\text { Relação } \\
\text { TF/TI *4 }\end{array}$ \\
\hline $\mathrm{A}_{1}$ & 39,64 & 39,98 & 3 & 2,20 & 3,5 \\
$\mathrm{~A}_{2}$ & 41,00 & 40,98 & 7 & 1,60 & 2,6 \\
$\mathrm{~A}_{3}$ & 39,40 & 39,59 & 0 & 1,40 & 2,2 \\
$\mathrm{~A}_{4}$ & 39,36 & 39,47 & 1 & 1,95 & 3,2 \\
$\mathrm{~A}_{5}$ & 39,80 & 40,29 & 0 & 1,55 & 2,5 \\
$\mathrm{~A}_{6}$ & 39,79 & 40,20 & 0 & 2,00 & 2,9 \\
$\mathrm{~A}_{7}$ & 39,64 & 39,99 & 2 & 1,50 & 2,4 \\
$\mathrm{~A}_{8}$ & 39,36 & 39,52 & 4 & 2,00 & 3,2 \\
$\mathrm{~A}_{9}$ & 39,78 & 40,12 & 0 & 1,55 & 2,5 \\
$\mathrm{~A}_{10}$ & 39,91 & 40,31 & 0 & 1,90 & 3,3 \\
$\mathrm{~A}_{11}$ & 39,40 & 39,53 & 0 & 1,60 & 2,2 \\
$\mathrm{~A}_{12}$ & 39,65 & 39,98 & 0 & 1,90 & 3,1 \\
\hline
\end{tabular}

*1 peso da amostra antes da expansão.

*2 peso da amostra após a expansão.

*3 no de grãos em relação ao peso 1 .

*4 relação entre tamanho final e tamanho inicial.

\subsection{AVALIAÇÃO SENSORIAL}

A qualidade do milho pipoca varia de acordo com a espécie, o tipo de solo e os cuidados no plantio, sendo avaliada por fatores como volume expandido, forma dos grãos, suavidade e sabor. A suavidade está normalmente relacionada ao volume expandido (SZCZESNIAK, 1963). 
A Tabela 5 apresenta os resultados da análise sensorial do milho pipoca expandido. 


\section{TABELA 5 - CARACTERÍSTICAS SENSORIAIS DO MILHO PIPOCA EXPANDIDO}

\begin{tabular}{cccc}
\hline & \multicolumn{3}{c}{ Atributos } \\
\cline { 2 - 4 } Amostras & Expansão $*$ & Cor $*$ & Maciez ${ }^{*}$ \\
\hline $\mathrm{A}_{1}$ & $3,1 \mathrm{a}$ & 2,7 acegikodv & $3,1 \mathrm{abcdeg}$ \\
$\mathrm{A}_{2}$ & $7,1 \mathrm{a}$ & $3,1 \mathrm{bfl}$ & $2,6 \mathrm{ae}$ \\
$\mathrm{A}_{3}$ & $4,4 \mathrm{a}$ & $4,3 \mathrm{abfls}$ & $4,3 \mathrm{ade}$ \\
$\mathrm{A}_{4}$ & $5,5 \mathrm{a}$ & 3,5 cgikptv & $3,7 \mathrm{abde}$ \\
$\mathrm{A}_{5}$ & $4,8 \mathrm{a}$ & 4,6 efhjlgux & $3,2 \mathrm{acdeg}$ \\
$\mathrm{A}_{6}$ & $4,5 \mathrm{a}$ & 0,6 ghjlmqux & $3,6 \mathrm{bdfg}$ \\
$\mathrm{A}_{7}$ & $5,6 \mathrm{a}$ & $4,9 \mathrm{ijmqux}$ & $2,7 \mathrm{cdfg}$ \\
$\mathrm{A}_{8}$ & $6,3 \mathrm{a}$ & $5,8 \mathrm{k} l m r u x$ & $2,8 \mathrm{adf}$ \\
$\mathrm{A}_{9}$ & $5,0 \mathrm{a}$ & 3,1 opqrux & $2,5 \mathrm{dfg}$ \\
$\mathrm{A}_{10}$ & $4,7 \mathrm{a}$ & $3,2 \mathrm{stux}$ & $3,4 \mathrm{dfg}$ \\
$\mathrm{A}_{11}$ & $5,3 \mathrm{a}$ & $3,1 \mathrm{vx}$ & $3,1 \mathrm{efg}$ \\
$\mathrm{A}_{12}$ & $5,8 \mathrm{a}$ & $4,7 \mathrm{vx}$ & $4,0 \mathrm{~g}$ \\
\hline
\end{tabular}

Letras diferentes na mesma coluna indicam diferença estatisticamente significativa pelo teste de Tukey, ao nível de $5 \%$ de probabilidade.

* Avaliados com o uso de escala não estruturada de $9 \mathrm{~cm}$.

No atributo expansão, as amostras não apresentaram diferença significativa entre si segundo avaliação dos julgadores. Pela escala sensorial, os grãos expandidos situaram-se entre as faixas regularmente e moderadamente expandida. No entanto, a maioria das amostras recebeu valores superiores a 4,5 (correspondente a regularmente expandida), demonstrando que, para os julgadores, o tamanho da amostra atingiu valores de expansão considerados aceitáveis. Analisando o tamanho final e a expansão (Tabela 4) verificou-se que, a amostra $A_{1}$ mostrou-se inversamente proporcional, pois quanto menor a média atribuída pelos julgadores maior o tamanho final dos grãos expandidos. Aparentemente, a análise física não apresenta relação com a análise subjetiva. $A$ amostra $A_{2}$ apresentou maiores valores médios para o atributo expansão e um dos menores para maciez. De acordo com GUADAGNIN (1996) quanto maior a capacidade de expansão maior será a maciez das pipocas. 
Quanto à cor, dez amostras apresentaram-se entre ligeiramente e regularmente amarelas, evidenciando homogeneidade para este atributo. A amostra de grãos com coloração amarela mais intensa, após o processo de expansão, foi a que apresentou valores mais próximos ao branco, diferindo das demais.

Verificou-se que a amostra $A_{6}$ apresentou a menor média atribuída pelos julgadores $(0,6)$, sendo caracterizada sensorialmente pela cor branca. Entretanto, a mesma amostra apresentou $57 \%$ dos grãos de coloração amarelo mais intenso na avaliação física. Observou-se portanto, que as amostras de grãos de milho pipoca mais amarelados obtiveram coloração branca mais acentuada após a expansão. Em relação a análise química dos grãos (Tabela 2), tais amostras apresentaram maior porcentagem de gordura e proteína, evidenciando que estes componentes podem ter afetado a coloração final do milho pipoca expandido.

Para o atributo maciez, todas as amostras enquadraram-se na faixa entre ligeira e regularmente macia, demonstrando grande similaridade de valores entre as diferentes amostras.

\section{CONCLUSÃO}

O milho pipoca produzido na região serrana do Rio Grande do Sul, mais especificamente na região de Nova Prata, apresenta características químicas e microbiológicas muito semelhantes e similaridade com marcas de pipocas encontradas no comércio local, estando todas de acordo com os padrões para cereais e derivados.

As amostras também se mostraram similares quanto aos aspectos físicos para tamanho, cor, peso, forma, volume e número de grãos defeituosos.

Sensorialmente, as amostras expandidas foram consideradas pela equipe de julgadores significativamente iguais para 0 atributo expansão, e apresentaram pequena variabilidade para cor e maciez, com tendência para cor amarela e ligeiramente macia.

\section{Abstract}

The aim of the present work was to evaluate physical, chemical, microbiological and sensory characteristics of popcorn produced in the state of Rio Grande do Sul and to compare it with imported commercial samples. Physical and sensory evaluation were also performed in popcorn after expansion process. The results evidenced a great similarity among the characteristics of all samples as for grains in natura, and for all the expanded grains. The biggest sensorial difference observed was in relationship to the color attribute. It was concluded that the popcorn produced in Rio Grande do Sul showed similar quality to the imported popcorn. 


\section{REFERÊNCIAS}

1 ASSOCIAÇÃO BRASILEIRA DE NORMAS TÉCNICAS. NBR12994: métodos de análise sensorial dos alimentos e bebidas. Rio de Janeiro, 1993. $2 \mathrm{p}$.

2 ASSOCIAÇÃO BRASILEIRA DE NORMAS TÉCNICAS. NBR14141: escalas utilizadas em análise sensorial de alimentos e bebidas. Rio de Janeiro, 1998. $3 \mathrm{p}$.

3 BRASIL. Ministério da Saúde. Secretaria de Vigilância Sanitária. Resolução RDC no 12, de 02 de janeiro de 2001. Regulamento técnico sobre os padrões microbiológicos para alimentos. Diário Oficial [da] República Federativa do Brasil, Brasília, n. 7-E, 10 jan. 2001. p. $45-53$.

4 CAMPBELL, A.M.; PENFIELD, M.P; GRISWOLD, R.M. The experimental study of food. Boston: Houghton Mifflin, 1979. $513 p$.

5 FDA. Bacteriological analytical manual for foods. Whashington: AOAC International, 1992. App. 3.85.

6 FACHIN, D.T.; SCHEER, A.P.; SAMPAIO, E. et al. Elaboração de pós para bebidas utilizando milho pipoca. Boletim do CEPPA, Curitiba, v. 11, n. 1, p. 11-16, 1993.

7 GUADAGNIN, J. P. Milho pipoca. Porto Alegre: Fundação Estadual de Pesquisa Agropecuária, 1996. 12 p. (Circular, 9).

8 HOSENEY, C. R. Princípios de ciência e tecnologia de los cereales. Zaragoza: Acribia, 1991. $324 \mathrm{p}$.

9 INSTITUTO ADOLFO LUTZ. Normas analíticas do Instituto Adolfo Lutz: métodos químicos e físicos para análises de alimentos. 3.ed. São Paulo, 1985. 533 p.

10 ISO. INTERNATIONAL ORGANIZATION FOR STANDARDIZATION. ISO 5497: sensory analisys: methodology. Guidelines for the preparation of samples for which direct sensory analisys is not feasible. Genéve, 1982. $4 \mathrm{p}$.

11 POMERANZ, Y. Functional properties of food components. New York: Academic Press, 1991. 565 p. 
12 SZCZESNIAK, A. S. Classification of textural characteristics. Journal of Food Science, Chicago, v. 28, n. 385, p. 385-389, 1963.

13 STATSOFT. Statistica. Tulsa, 1991. $935 \mathrm{p}$. 